\title{
A Theoretical Framework for Data-economising Appraisal Procedures, with Applications to Rural Development Planning
}

Deryke Belshaw ${ }^{1}$

. . . it is as easy and as artificial to import oversophisticated policymaking techniques as it is to import inappropriate technology. Policy analysis has been biased toward mathematics-intensive analysis, at the expense of policy techniques that may be less sophisticated but more relevant for the major problems confronting the country. Attention in the future must be given to the basic needs in policymaking, just as to the basic needs in the production and consumption pattern of the economy.

G. M. Meier (1977:223)

\section{Introduction: Information, Error and the Costs of Development Decisions}

Data-economising is a relative term indicating that a given decision can be made on the basis of less data - and therefore more rapidly or less expensively than would otherwise have been the case. A dataeconomising approach ${ }^{2}$ might prevent the accumulation of superfluous or redundant data, although the case for collecting very relevant data could be rejected because it is judged that the value of having it would be less than the additional costs (whether time or other resources) required to produce it . The first situation is comparable with assessment in terms of cost: effectiveness; the second with cost: benefit analysis.

In this article the term 'appraisal' is used with a wide meaning which includes not only ex ante project appraisal but all areas where data are collected and analysed to assist development decision-making in the public sector, including monitoring and evaluation of development options.

Information for an adequate rural development appraisal system for informed rational choice between alternative policies and projects under a system of multiple development objectives, is usually time consuming and costly to obtain. If all the important questions were to be completely specified, many of the key social relationships would be difficult to observe. let alone quantify.

'A revised version of a paper given at the Conference on Rapid Rural Appraisal held at the Institute of Development Studies. University of Sussex, in December 1979. The author is indebted to his colleagues Nick Abel and Gilroy Coleman for helpful discussions: the remaining failings are his responsibility.

${ }^{2}$ See. for example. the repertoire of techniques described in Chambers' (1980) summary of the Rapid Rural Appraisal conference.
It is now widely recognised that such rational decision models are unsuitable tools for handling very large projects (see eg Coyle 1972:94), major structural changes or situations of massive market failure (Meier 1977:221). In other words, it is illusory for data producers to argue that the offsetting benefits for the costs society incurs in obtaining information will be generated from successive approximations towards a single optimal strategy - although much of the literature of economic planning would have one believe that this were the case.

An alternative framework for the application of rational information-using processes can be constructed from the more pragmatic and limited objective of identifying and reducing major errors in the policy-making processes of society. The less ambitious nature of this approach in itself reduces the level of demand for information. The framework is set out in more detail below, especially in sections 3 and 4 , but the implications for data and information generating activities can be summarised briefly here. Decisions about how the public sector should act-including the decision not to act - carry a higher probability of error the poorer the quality of information about the consequences of each action. The greater the emphasis on rural development planning, the stronger the tendency for costs falling on the rural population to arise from erroneous public sector action. In this case, information priorities should be determined after some kind of decision inventory (see section 3 ) has been completed.

Clearly, the likelihood of error is enhanced when public sector decisions are based on the inferred rather than the directly-expressed preferences of the target population. Whilst the error-reduction objective suggests the need to collect more data where decisionmaking is concentrated in the public sector, an alternative approach consistent with that objective is to devolve decisions onto the private sector, especially where the project size is small and where data are costly to collect. This would suggest increasing reliance on private market transactions, especially if the distribution of private income is becoming less concentrated, whilst providing improved market information, legal protection, etc. to the producers and consumers operating in those markets. Of course, private interests in the public sector will probably oppose the devolution of statutory responsibilities in this way (the mirror image of private opposition to

Bulletin. 1981. vol 12 no 4. Institute of Development Studies. Sussex 
public sector intervention in the free market). The radical, consciousness-raising information function would then find its main role in critically examining the costs of inefficiency, elite privilege, etc, in the public sector?

The major focus of this article, however, concerns the process of generating information for those decisions in the public sector which are intended to benefit, but which may be detrimental to, the interests of the rural majorities of the Third World populations. A theoretical framework is sought which will indicate more efficient and equitable approaches to the generation of the relevant information for improved public sector decision-making. Section 2 examines concepts drawn from the economics of information; section 3 the Popperian model of error reduction in public decisionmaking; section 4 the application of cybernetics principles to the design of sequential planning procedures; section 5 the role of formal models of the development process for use in sequential planning, and section 6 examines the information implications of the location of decision-making responsibility at alternative levels in the politico-administrative system. Finally, section 7 outlines a unified framework for selecting data-economising procedures for development planning.

\section{The Economics of Information as a Source of Data-economising Principles}

Since information can be viewed as an intermediate product entering into a further production process, the generation of information can itself be analysed as a production process. In principle, the optimal level of information (and ignorance) can be identified by considering the relationship between the costs of obtaining additional information and the additional value or benefit derived from it in use in subsequent decision-making. Figures 1 and 2 reproduce an analysis of information-generation in a production economics framework (McDonough 1963). Figure 1 indicates a lagged response in terms of the quantity of information generated about an identified problem compared with a decision-maker's realisation of the need for additional information prior to the selection of the problem solution. Since it is assumed that more questions will be raised than can be answered, it follows that an information gap remains even at the close of the process. In Figure 2 (where the horizontal axis now shows levels of information output) the assumption that total cost of production and value in use curves are known enables the determination of the privately optimal level of information.

\footnotetext{
${ }^{3}$ For a n example of the radical information role in a country where the degree of public sector control has been rapidly expanded, see Issa Shivji's critique (1975) of state capitalism in Tanzania.
}

As a conceptual model this has certain advantages. It emphasises value to the information user as the primary justification for the information-generating activity; it indicates the physical difficulties of knowing everything one would like to know about a problem, and it underlines the existence of a level of ignorance whose further reduction is insufficiently beneficial or remunerative. At the same conceptual level, indeed, the analysis can be taken further. Principles concerning the choice of alternative techniques of information production and the possibility of substituting cheaper factors for more expensive ones (indicators for more complete data arrays, rules of thumb for individually specified models, etc) could be illustrated in the same way. Similarly, it can be envisaged that with a given stock of information-generating factors (specialist manpower, a survey budget, etc) net value would be increased by identifying higher return decision areas in which the output of data is utilised. Finally, the static cost and value curves can be recast into a discounted cash flow model. The time required to collect additional data represents a probable stream of benefits foregone from deferring the investment decision; this is over and above the direct costs of data collection. Total extra costs must be outweighed by the expected extra benefits arising from the additional data once the project starts.

Nevertheless, the simplistic assumptions underlying the model may also mislead. In reality, the cost curve may assume a stepped rather than a smooth function reflecting the 'lumpy' nature of data-processing capacity or the need to add new disciplinary specialists. The problem then takes the form of whether or not to "make do" within the maximum information available on the lower step. The assumption of certain knowledge ex ante about both the production function and the value of information in use is quite unrealistic; relaxing this assumption highlights the value of such uncertaintyreducing investment in information as pilot projects and field trials. Other heuristic procedures are widely adopted in order to at tempt to identify the areas of use where additional information will be of greatest value; in development planning such concepts as the leading sector, the operative constraint, bottlenecks and target groups are all intended to divert effort away from attempts to understand comprehensively and plan for the whole system into more productive areas.

A major problem in the public sector, however, is the fact that the cost-return conjuction within firms operating in the market place is replaced by the institutional separation of data producers and costs on the one hand and information-users with a fuzzy perception of benefits on the other. This situation permits the entry of institutional and professional interests on the data producing side. Consequently, 


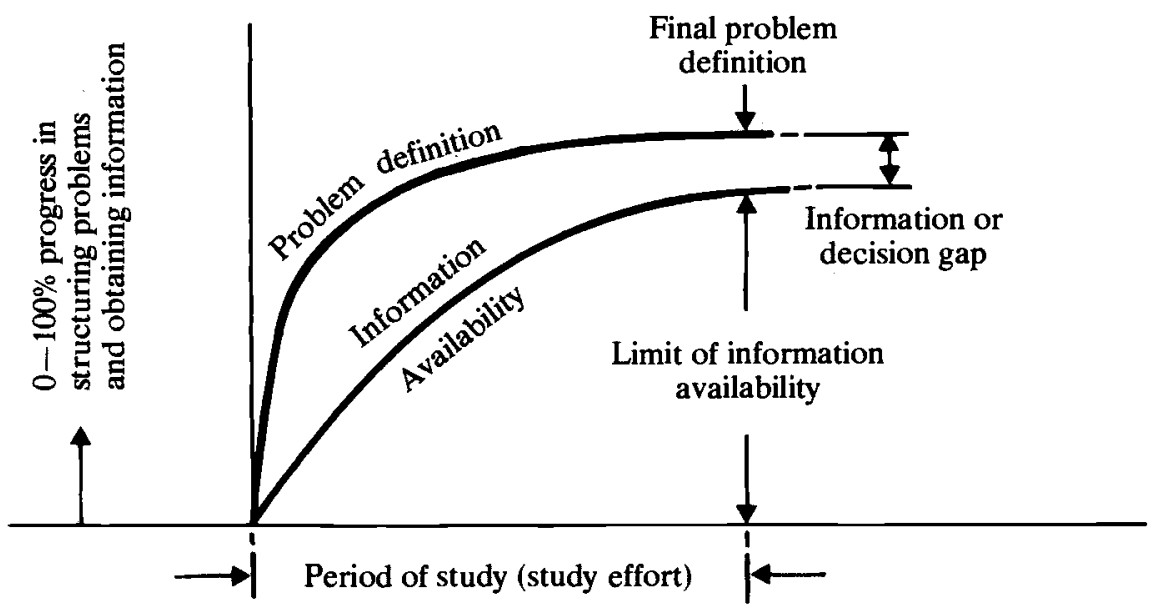

Source: McDonough (1963)

figure 2

Principles of cost-benefit analysis of information

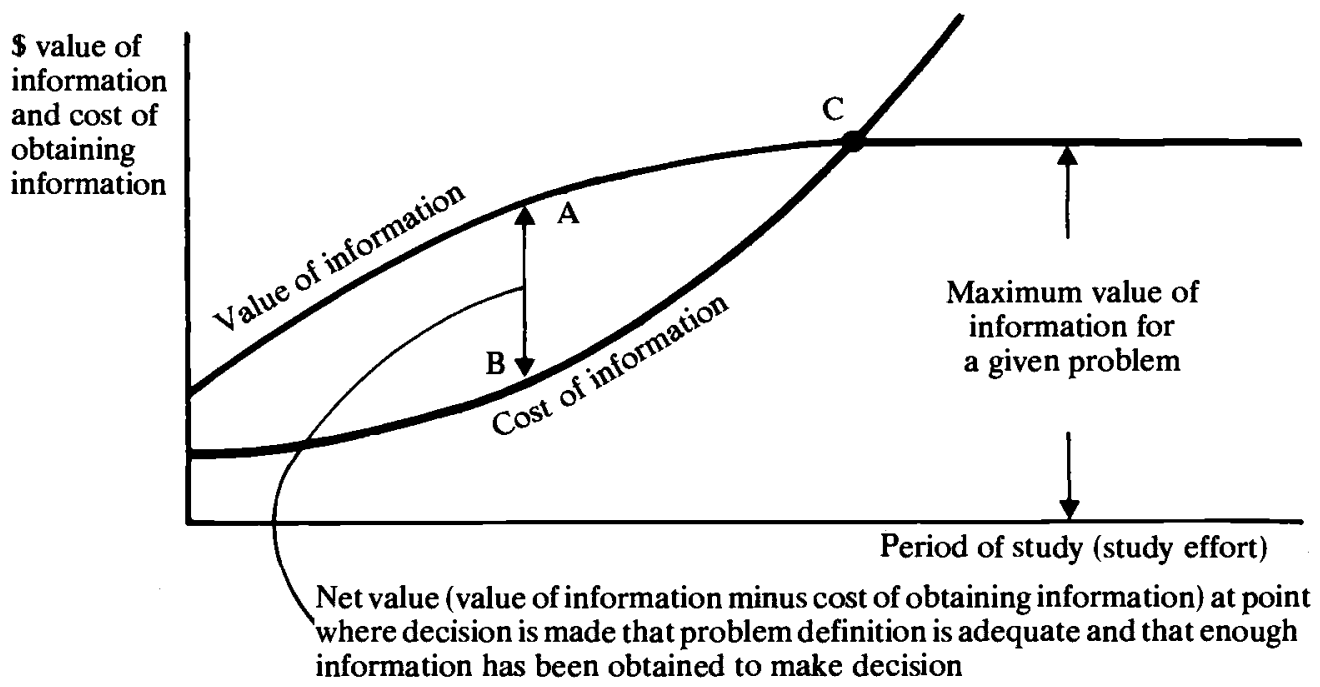

Source: McDonough (1963) 
there is often a need for procedural reforms which will reassert the link between the two: attempts to apply costbenefit analysis and programme performance budgeting systems procedures to research activities in the public sector provide examples of this (Barnard 1975:300). In practice. the estimation of both costs and benefits is a highly subjective procedure but a framework which raises the relevant questions at the right time usually assists the process of learning from past errors in subjective decision-making: that is. the state of the art can be improved by making assumptions explicit.

Finally, we should note that the economics of information uses a micro-economic mode of analysis. The concepts relate to the costs and returns or benefits from information in concrete. non-aggregative situations. They are consistemt with the identification of specific data priorities for problem-solving or errorreduction. rather than with attempts to comprehensively model an overall economy or sector.

\section{Error Reduction as a Guiding Principle in Equity-oriented Development Planning}

In The Open Society and its Enemies (1945) Popper formulated an alternative social welfare function which avoids the conjoint problems of operational infeasibility and yet insatiable demands for information associated with utilitarian optimality formulations ${ }^{4}$. Two concepts originated with Popper. The first is to minimise unavoidable suffering for the ethical evaluation of policies. McGee (1973) has summarised the operation of this principle as follows:

instead of encouraging one to think about building Utopia it makes one seek out. and try to remove. the specific social evils under which human beings are suffering. In this way it is above all a practical approach. and yet one devoted to change. It starts from concern with human beings. and involves a permanent. active willingness to remould institutions.

Although the phrase 'avoidable suffering' gives little guidance to operational questions concerning identification. design and selection of alternative solutions. it nevertheless deals with classes of essentially tangible and knowable factors which are intelligible to policy makers and major sections of the population. It starts. in other words. where the people are.

The second concept and of greater relevance to the role of information in policy making is Poppers (1959) extension of his philosophy of scientific knowledge - the principle of falsifiability - to the realm of public sector

It also avoids the criticism of excessive restrictiveness of criteria which Sen (1979) has levelled more recently at the "welfarism" assumptions in welfare economics. decision-making. McGee (1973:75-77) helpfully summarises the argument:

A policy is a hypothesis which has to be tested against reality and corrected in the light of experience. Detecting mistakes and inherent dangers by critical examination and discussion beforehand is an altogether more rational procedure. and one as a rule less wasteful of resources. people and time. than waiting till they reveal themselves in practice. Furthermore it is often only by critical examination of the practical results. as distinct from the policies themselves. that some of the mistakes are to be identified. For. in this connection. it is essential to face the fact that any action we take is likely to have unintended consequences.

Obtaining the evidence of not achieving desired effects-the negative feedback which permits corrective action to be taken - suggests the institution of monitoring and evaluation procedures: these are examined in more detail in the following section. It is also clear from Popper's emphasis on the importance of both the generation of the hypotheses to be tested and the design of the test itself. that the quality of information which is available before the 'test is carried out is of critical importance. The main issue here is the weight to be placed on different categories of information required for the design and testing of alternative policies and projects. It is proposed that the magnitude of error costs and their distribution relative to the capacity of error recipients to bear them. can indicate a commonsense set of priorities for information generation. Three levels of policy error occurrence need to be distinguished: in ascending order of cost these are the individual project or policy implementation level. the project or policy design level and the strategy (the set of projects and policies) design level. Failure of a project ex post to achieve its intended development impact may arise from deficiencies in its implementation or design.

The determination of information priorities could proceed by way of a decision inventory at each of these levels with emphasis on identifying the type. probability and consequences of erroneous judgement which would follow from information deficiency. As in scientific hypothesis testing procedures (eg Fuller and Lury 1977:156). the types of error fall into two categories:

a) An erroneous rejection of an apparently sound strategy or project or method of implementation ( = non-falsifiable hypothesis) because available information underestimated the proposal's potential or over-estimated the range or severity of possibly adverse factors (Type I error).

b) A failure to reject an inherently weak strategy. etc ( $=$ false hypothesis) because available 
information over-estimated the proposal's potential or overlooked strongly adverse factors or underestimated the severity of those same factors (Type II error).

As an example. let us consider a decision in rural settlement planning to locate $n$ families in a village at site $X$ where the local environment is unable to support them at an acceptable standard of living. This is a Type II error. A decision not to utilise a village site which could maintain a certain number of families at or above the acceptable level is an example of a Type I error. Type II errors cause suffering. require remedial attention with varying degrees of urgency (depending on the number of people involved. the severity of the effects etc) and reduce popular confidence. Information for screening out Type II errors ex ante has particularly high priority unless there are ways of sequencing the decisions over several phases where the early outlays are small and themselves generate additional information (see section 4 below). The costs of individual Type I errors are usually less severe. although their cumulative effects can be considerable: they need to be identified and rectified in the subsequent planning cycle.

The possibility of implementing such an approach seems promising precisely because it suggests heuristic aids to decision making about the generation of information which is couched in the very issues and consequences which policy-makers themselves are most concerned about. The approach does require. however. a greater openness than is usually found in governments to the examination and exploration of errors resulting from past decisions and to institutionalising ways of learning from experience eg through case-study training materials for officials and popular representatives.

\section{Data-economising Opportunities with Management Cybernetics}

Cybernetics - the science of communication and control in man and machine - moved from its original fields of application in the 1940s in biology and engineering into business management (eg Johnson et al 1963) and regional planning (McLoughlin 1969) in developed countries in the $1960 \mathrm{~s}$. The first theoretical application to Third World development planning was published in 1970 (Kulp 1970). Field design and independent evaluation of a set of management procedures for six multisectoral area based plans were built into Kenya's Special Rural Development Programme in 1971-73 (Belshaw and Chambers 1973. Chambers 1974). Some of these procedures have been replicated in a number of other countries. whilst ongoing monitoring and evaluation systems for the successive improvement of project implementation and impact have received considerable attention by international donor agencies in recent years (eg USAID 1973. IBRD 1976. Imboden/OECD 1978. UN 1978).

A cybernetics or information systems approach to planning builds an adaptive control or formal 'learningby-doing dimension into the sequence of plan formulation and implementation. This takes the form of feedback procedures for monitoring implementation progress and evaluating socio-economic impact. The approach implies the possibility of a trade-off between information generated in the period up to the selection of the problem solution (as in McDonough's model) and the information generated in the course of implementation. Since part of the latter will be a byproduct of management processes which would be necessary in any case. the overall cost of information of a given quality will be reduced. The project design (and possibly its objectives too) is not set rigidly at the time of project selection but may be successively revised in the light of feedback information. This feature is consistent with Poppers stress on the high probability of initial error in the design of public sector policies or projects.

The rapid detection of error in the project design requires a quasi-experimental formulation where hypotheses about the patterns of interaction between key variables are made explicit. In a development plan which consists of production and social services projects operating in a typical mixed economy where public production projects therefore provide intermediate goods to private producers eg production credit programmes and training for peasant farmers or fishermen. at periodic intervals the state of private consumption in production (and the effect of public policies in the preceding period on them) is observed in order to modify the operation of those services in the subsequent period. Unfortunately. recent literature has neglected the question of process modelling (cf Imboden 1978:71-74. UN 1978:30) with the attendant risk that erroneous planning assumptions will go undetected and attempts will be made to force the private process to fit the projects objectives. In principle the emphasis on feedback from lower to higher management and policy-making levels should bring erroneous assumptions to light. If highly centralised decision-making structures and inflexible management hierarchies are retained. however. the risk is high that junior management will falsify feedback information in order to protect their own positions. The information system then becomes a smokescreen rather than a searchlight.

\section{Data for Dynamic Models of the Rural Development Process at the Local Level}

It was proposed in section 4 above that development planners need explicit models of the assumed nature 
of the rural development process. These are required for two possible situations: using the terminology developed in section 3 above, these are:

(i) Periodically, as and when major type II errors are found to have occurred. The critical assumptions embodied in the original strategy or project will need to be checked. These assumptions will usually relate to (a) those aspects of the development process with which the public intervention was interacting. and (b) the way the latter was expected to alter the development process. New feedback information may reveal errors in those assumptions, help explain why the initiative failed to achieve its objectives and indicate whether the project should be modified or abandoned. If erroneous process assumptions remain unrecognised, the tendency will be either to continue to force the process to conform to the public initiative, or to falsify the feedback data so that they are consistent with the projected designs or targets: (ii) Continuously, within cybernated evaluation and plan reformulation activities, to reduce the risk of rejecting or overlooking public sector initiatives which would make a strong contribution to the overall set of national development objectives ie to reduce the occurrence of type I errors. The comprehensive identification and monitoring of at risk or target groups in rural areas, for example, should be accompanied by causal analyses of the relevant condition leading to the identification of a range of solutions.

Rural sectors are large and complex systems; potentially, the array of data required to formulate accurate policy advice within a multi-objective context is immense, given the need to understand the interaction of technical, economic, social and political factors. The data available are far from complete in Third World countries. Paradoxically, however, a large part of what is available is often not used - or even usable for planning purposes. Are principles and procedures available for reducing the information requirements for understanding rural development processes and responses? It is taken as axiomatic that some minimum quantity of information is required about each of the grass-roots components of the rural sector-farm, household, village and social interest group systems. This alone appears rather daunting. Nevertheless, from the potentially vast amount of relevant data, the limited application to date of such criteria as utility in decision-making, relative cost of data, effectiveness of alternative information-generating techniques and economics under 'continuous' decision-making pro-

\footnotetext{
${ }^{5}$ Problems commonly arise in the form of obsolete data; inappropriate aggregation of data (eg summing for administrative areas the characteristics of quite different farming systems); missing variables (eg nonfarm income, non-official prices); and confusion in the underlying concepts (as in calculations of 'the cost of production' or the estimation of net (versus gross) benefits).
}

cedures suggest that improved models of process and response can be constructed from much smaller arrays of data. The remainder of this section represents an attempt to apply these criteria.

In the conventional rational planning approach, notionally at least, large quantities of planning data are required in order to design and select the optimal strategy. At the farm and household levels, several country-wide sample surveys are advocated (but less often undertaken or completed in time). They often comprise the following types:

(i) Agricultural censuses: estimation of farm holding and herd number and size; crop areas and yield levels;

(ii) Farm management surveys: estimates of enterprise input-output coefficients: farm incomes: capital formation; interfarm efficiency comparisons;

(iii) Food consumption and nutrition surveys: estimates of adequacy of nutritional intakes based on direct measurement of diets (rarely conducted over the full agricultural cycle).

In the writer's view, these specific types of statistical exercise yield only limited utility for rural development planning. This is largely because, firstly, updated country-wide data are only rarely available at the time when strategies are being formulated; secondly, even if they were available, the survey results do not yield the kind of problem-identifying information about the distributional aspects of development which the resolution of equity questions requires ${ }^{\circ}$ and, finally, the more useful information which in principle could be obtained from these surveys - such as tested explanations of observed variations in inter-household consumption and inter-farm efficiency - requires skills in techniques of model-building and hypothesis testing in non-available quantities although the levels of skill required has been exaggerated through an undue emphasis on sophisticated quantitative methodology (Biggs 1974).

With certain simplifications however, agricultural statistics could become much more useful for planners and decision-makers. For example:

(i) Replacing large, detailed farm management surveys with analyses of a small number of representative farms and pilot projects. These studies would not attempt to provide aggregate estimates of production or income but would be used in policy or project design and selection. The extra value of the information gained from the multi-disciplinary teams is likely to justify the additional skilled manpower required (see Collinson 1974);

\footnotetext{
'Unless, as in certain land-surplus areas, the rural poor are synonomous with farm households; even then intra-household consumption variation will not be measured.
} 
(ii) National agricultural censuses. such as the FAOsupported decennial world census of agriculture: are virtually useless for rural development planning. Long term trends. such as the effect of population pressure on farm size. can be gathered much more cheaply as components in population censuses and surveys. The planners urgent needs. on the other hand. include more reliable 'early-warning' systems of impending failures in the crop or grazing production systems. Combinations of remote-sensing techniques and ground verification give promise of useful advances in this area. These innovations clearly have relevance for rural development objectives. as the most deprived groups will tend to suffer the consequences of catastrophes more severely than the better-off. Hazard avoidance and amelioration procedures should become integral parts of rural development strategies;

(iii) Parallel measures in the area of nutrition surveillance. especially the use of simple mass physiological measurement to monitor the mediumterm effectiveness of policies aimed at relieving child malnutrition (WHO 1976) are also highly relevant for rural development strategies both as indicators of specific food consumption deficiencies and as a general index of changes in rural welfare.

At the level of villages and other local interest groups. insights into socio-political mechanisms causing continuing deprivation can be generated by the participant observation research methods used by social anthropologists. However. Long (1977) has reiterated the problem of the unknown level of representativeness of findings from these studies: he proposed that social anthropologists should work at the multi-village or regional level to enable them to make more generalised statements. The limitations of a single disciplinary perspective. however. would still remain. An alternative four-element procedure is suggested below.

Economic analysis of the whole village system, rather than of one component (such as farms). has been proposed by researchers at the Institute of Development Studies at the University of Sussex. Connell and Lipton (1977) have advocated the widespread construction of village typologies which will identify the nature of the constraints on decisions taken by families within the village. Their scheme has been criticised by Kirkpatrick (1978) for failing to indicate how analyses of the lowerorder sub-systems of farm and household decisiontaking would be integrated into this framework. A statistical application of their procedure to Indian survey data (Dasgupta 1977) produced an unenlightening typology: villages falling into the two contrasting groups (more advanced and less advanced) with a third group in the middle. How far this result arose from the use of surveys which were not designed to examine all the operative constraints is not clear.? Biggs (1977) has proposed the construction of formal analytical models of village resource allocation which would incorporate efficiency and distributional dimensions. Such models. however. would need to be extremely complex and many variables in them would pose major problems of quantification: even if it were used as a research tool the prospects appear poor for obtaining reliable findings from quantified techniques of analysis.

An alternative approach which would seem to be more consistent with the probable implementation and $R \& D$ capacities would comprise (a) the rapid assessment of village-level resources and services through some kind of 'facilities register' (eg Lundquist 1975): (b) a qualitative analysis of the ways in which the local socio-political system may frustrate deprivation-alleviation objectives; this could be derived from a sociological evaluation of a few existing or new pilot schemes planned with this orientation; (c) on the basis of the village inventory. a survey of a small. purposively selected sample of 'representative villages' to assess the impact of, and differential response to, public sector policies and projects and other changes in the village and family environment: and (d) the establishment of simple monitoring and evaluation procedures in a small sample of villages in order to pinpoint problems at an early stage.

In most societies a broad map of social groups and classes may be useful for rapid identification of probable causes of poverty arising from inequitable access to resources. use of market or political power. etc. However. in the writer s experience in Tropical Africa. a rigid class framework has little explanatory value because new interest groups emerge from the bureaucracy. the military or political party cadres. whilst the behaviour of ethnic groups and occupational strata rarely follows predictable class lines. A more flexible approach seems desirable. based on the identification of conflicting economic interests. These would be analysed using multi-disciplinary models embodying. inter alia. institutional economics. behaviourial explanations of administration and management. social anthropology and welfare economics.

The objective would not be the production of completely specified models of long-run social change-with the attendant problem of stating the key hypotheses in forms open to refutation - but rather to identify specific ways in which benefits intended for target groups are diverted. or to show why particular methods of intervention can accentuate dualistic or other unequal distributional patterns. with immediate implications

\footnotetext{
${ }^{7}$ The immense labour involved in keeping a comprehensive village typology up to date would also seem to be a major drawback of this approach.
} 
for public sector policy or for public opinion formation.

\section{Reducing Information Demand in the Public Sector}

Because internal economies of scale operate strongly in this area, problems of information deficiency for public sector decision-making will tend to become severe, the larger the number of separate decisions to be made, and the greater the number of hierarchical levels through which information has to pass. Information tends to get lost or distorted in its upward transmission, especially when it is aggregated with information from other lower level units. A number of questions arise, in relation to these issues:

(i) What are the advantages and disadvantages of collecting and holding data in disaggregated form up to the point of decision?

(ii) How far should decisions be decentralised to lower levels within the public sector hierarchy?

(iii) What are the advantages and disadvantages of devolving certain decisions to the private sector ie reducing to zero the demand for data for immediate decision-making purposes.

It is readily apparent that these issues are particularly relevant for the rural sector, given the generally atomistic structure of decision-making in production, consumption and exchange, its geographical extensiveness and its ecological and social diversity. The design of a general framework for data-economising appraisal procedures, therefore, should be informed by such factors as the internal structure and overall scope of public decision-making. Table I compares two decision structures for development planning; the first is a disaggregated system which produces comprehensive plans at each hierarchial level but retains central control over all resource allocation decisions. The second is a system where rural development responsibility has been decentralised to the next lowest level-that of the state.

Plans for lower-order areas need to be accurately assessed and integrated at each higher stage. It seems probable that once a certain number of units is exceeded a significant decline in planning accuracy must result. On these grounds, Richardson (1978) suggests a maximum of 12 units at each hierarchial level. With the disaggregated planning system, five information transfers are required before final decisions are taken. The probability of serious information loss and distortion is high. In the decentralised system, the number of information transfers is reduced to three. In the example this is achieved partly through decentralisation to the state level, and partly by using multivillage area-based projects (permitting transgression of administrative area boundaries in favour of river basins, agro-ecological zones, etc), instead of attempting to provide each village with its own comprehensive development plan (for an illustration of such a hierarchy-shortening arrangement in a regional plan context, see Belshaw (1979).

Clearly, many different patterns can be devised to reduce the information transfer problem, nor need a uniform system be adopted; some decisions may be retained centrally and others decentralised or devolved onto the private sector. Major policy issues, such as the role of the public sector, national unity versus

table 1 Information transfers with disaggregated and decentralised planning systems

\begin{tabular}{|c|c|c|c|c|c|c|c|}
\hline & \multicolumn{3}{|c|}{$\begin{array}{l}\text { disaggregated administrative } \\
\text { area planning }\end{array}$} & \multicolumn{3}{|c|}{$\begin{array}{l}\text { decentralised area-based } \\
\text { project planning }\end{array}$} \\
\hline & & $\begin{array}{l}\text { no per } \\
\text { higher uni }\end{array}$ & total no & $\begin{array}{l}\text { information } \\
\text { transfers }\end{array}$ & $\begin{array}{l}\text { no per } \\
\text { higher unit }\end{array}$ & total no & $\begin{array}{l}\text { information } \\
\text { transfers }\end{array}$ \\
\hline \multicolumn{2}{|c|}{ National planning } & 1 & 14 & \multirow{3}{*}{$\begin{array}{l}-5 \\
-4 \\
-3\end{array}$} & 1 & 1 & \multirow{3}{*}{-3} \\
\hline State & , & 10 & $10 \overline{4}$ & & 10 & $10 \triangleleft 7$ & \\
\hline Region & , & 10 & $100 \triangleleft$ & & 10 & 1008 & \\
\hline District &, & 10 & $1000 \bar{\jmath}$ & & - & - & -2 \\
\hline Areabased & , & - & - & -2 & 12 & $1200 \frac{4}{7}$ & \\
\hline Division & , & 10 & $10000 \triangleleft$ & -1 & - & - & -1 \\
\hline Village & , & 12 & $120000^{-}$ & & 100 & $120000^{-}$ & \\
\hline
\end{tabular}


regional autonomy and the achievement of popular participation objectives in development decisionmaking, are also involved here, so that the goals of error reduction and data-economising are unlikely to be allowed to resolve these issues in isolation. Conversely, however, any major change in the formal political structure and in the siting of key decisions necessitates changes in the flow of information. This may provide an opportunity for reducing the proportion of information moving towards the centre.

\section{A Unified Data-economising Framework with an Illustrative Set of Procedures}

This framework begins with the recognition of the twin impossibilities of comprehensively modelling socioeconomic reality and identifying a single optimal pattern of resource allocation which a country should adopt (section 1). In the absence of comprehensive modelling and planning, it follows that additional expenditures to describe a previously neglected aspect of society cannot be justified merely by appeal to the academic 'addition to knowledge' criterion, since it is not certain that the additional data can be used immediately nor, given the high levels of obsolescence characterising socio-economic data, that they are worth storing for future use. Justification must be sought, therefore, using some other criterion deriving from an expected consequential improvement in public decision-making (a similar critique pertains to 'applied' research designed on traditional lines which is concluded before the indicated findings are subjected to testing and use under practical conditions; see Belshaw, 1976).

The need for a clear criterion of social justification is underlined by a consideration of the costs of production of information and the implication that in all situations there will be some optimal level of ignorance beyond which investment in further data generation cannot be justified (section 2). This further suggests the risk of the transfer to low-income countries of inappropriate data-requiring techniques of analysis from countries with different factor endowments and relative costs. In the public sector additional data are neither sold in the market place nor used directly within the dataproduction institution. What operational criterion, therefore, can be used to assess the expected value-inuse - the benefit side - of additional data available for public decision-making? Quality of decision-making can be assessed in terms of the frequency and magnitude of error, the consequences of that error and the speed with which it is recognised and countered. If an equity-orientation is present in public policy, the severity of the consequences of the error can be assessed in terms of its impact on those affected relative to their capacity to absorb it. The benefits from additional data can be envisaged, in a tangible sense, in the resulting reductions which can be made in social costs of this type. Such criteria are also consistent with Popper's stress on the goal of error-reduction in the public policy field, with the collorary that projects and policies should be checked for evidence that they are not achieving the results intended (section 3). Also, error analysis in scientific hypothesis testing suggests a systematic approach to the identification of possible sources and consequences of error in public decisionmaking and therefore to the identification of data priorities where this could be expected to reduce the probability of error."

Since errors cannot always be anticipated however, the question recurs about how rapidly they can be detected, and corrected for, after the event. This leads to a consideration of the value of monitoring and evaluation procedures, and particularly to the possibility of partially substituting continuous feedback data for ex ante investigation (section 4). This becomes especially attractive if much of the feedback can be provided cheaply as a joint product from project implementation and if an earlier start can be made because the initial data collection phase can be shortened. The introduction of a management information system approach, however, has more radical implications.

If evaluation is to lead to the accurate reformulation of projects and policies the explicit statement, in testable form, is required of the initial assumptions concerning the key relationships between projects and policies (and the overall strategy) on the one hand and the development process on the other. Simple models are needed which avoid the temptations of comprehensive coverage, rigidly preconceived categorisation and non-refutable speculation about long-run change."

Finally, in administrative structures with elongated hierarchical arrangements, plan formulation and feedback information is likely to suffer considerable loss and distortion. Opportunities should be explored, therefore, which would enable the decentralisation of decision-making to lower levels within the public sector, to create forums for popular participation and to devolve small-scale decision-making onto local communities and the private sector.

The choice of data-economising procedures would be influenced by specific circumstances, including the

\footnotetext{
${ }^{8}$ Alternative approaches to the problem, which are not discussed in the paper as they are not primarily concerned with data issues, include compensating the victims of erroneous public decisions after the event and risk-sharing between the public and private sectors (subsidies, income floors, welfare schemes, etc).

${ }^{9}$ Marxist class conflict models - as opposed to models which incorporate empirically observed answers to questions raised by the Marxist paradigm - appear to satisfy the criterion of simplicity more easily than the other requirements.
} 
characteristics of the development process, the set of development objectives, the availability and opportunity costs of resources for data collection and the stock of relevant knowledge. In total, the set of procedures should interact to form an alternative information system replacing, rather than being superimposed upon, other less cost-effective methods of data collection. Examples given in the paper were drawn from the rural sector. Summarising these here serves to illustrate a larger information system without implying that the particular set of procedures are appropriate to all rural situations.

(i) In order to identify data priorities, a decision inventory is undertaken in the relevant sector. This examines projects and policies currently being implemented, or under consideration, in terms of the possible types and sources of error, the groups likely to be affected and their relative capacity to bear the resulting costs;

(ii) The key assumptions, explicit or implicit, in the relationships between (a) project and policy design (b) development strategy and (c) development process are set out in the form of testable models or hypotheses;

(iii) In order to reduce the reliance on error-prone 'blueprint planning', formal R \& D procedures ${ }^{10}$ are incorporated into a continuous planning process;

(iv) Monitoring and evaluation ( $\mathrm{M}$ and $\mathrm{E}$ ) procedures are introduced which replace existing (usually nonfunctional) reporting systems. This must be preceded by their testing and modification for local circumstances, the production of training materials and the use of a pilot scheme as a practical training ground;

(v) Feedback information for the $M$ and $E$ system is utilised to examine the set of consequences from initial public sector inputs to final development impacts. This would indicate short-run effects at the level of the farm and rural household, identify any unanticipated problems arising at the level of the local rural community or target group; and assist with testing initial planning assumptions (ii above):

(vi) The scope is examined for further reduction in public decision errors by decentralising or devolving decisions towards the rural grass-roots, as well as the case for more wide-ranging administrative reforms to accompany the introduction of the overall integrated management information system.

A commonly prescribed solution for discerned inefficiencies in the production of data for development decision-making is that dialogue should occur between

\footnotetext{
"Including the more systematic use of search procedures, pilot projects and field trials; extending the 'parallel research design' approach (Abernathy and Rosenbloom 1969) into the project implementation and evaluation stages and designating a set of representative rural areas as field laboratories for testing alternative strategies (as with Kenya's former Special Rural Development Programme; see eg Livingstone 1976).
}

'planners' on the one hand and statisticians and research workers on the other. Planners are urged to indicate their data priorities with tolerances for accuracy and timeliness. In the writer's experience planners engaged in blueprint planning are unwilling to do this, because the identification of data deficiencies undermines the authority of their own output. Consequently, the professional concerns of the data producers continue to dominate the choice of data-producing procedures. The separation of planners from the $R \& D$ and implementation activities, therefore, is itself a major cause of the problem of inefficient data collection methods. The solution to this problem is seen to lie in the introduction of integrated development management structures which are enabled to function through an effective management information system. This emphasis is itself reflected in the central components of the unified theoretical framework.

\section{References}

Abernathy, W. J. and R. S. Rosenbloom, 1969, Parallel Strategies in Development Projects, Management Science, vol 15 no 10 , pp $486-505$

Barnard, C. S., 1975, 'Data in agriculture: a review with special reference to farm management research, policy and advice in Britain', Journal of Agricultural Economics, vol 25 no 3, pp 289-331

Belshaw, D. G. R., 1976, 'Appropriate methodology for development research', IDS Bulletin vol 8 no 1, pp 8-16

-1979 , 'Regional planning in Tanzania: the choice of methodology for Iringa region', Discussion Paper 24, University of East Anglia, School of Development Studies

- with R. Chambers, 1973, 'A management systems approach to rural development', Discussion Paper 161, Institute for Development Studies, University of Nairobi

Biggs, S. D., 1974, 'The role of linear programming methods in rural policy planning in developing countries, Discussion Paper 57, IDS, Sussex

-1977, 'Agricultural models and rural poverty', IDS, Sussex, mimeo

Chambers, R., 1974, Managing Rural Development: Ideas and Experience from East Africa, Scandinavian Institute of African Studies, Uppsala

-1980, 'Rapid rural appraisal: rationale and repertoire', Discussion Paper 155, IDS, Sussex

Collinson, M. P., 1972, Farm Management in Peasant Agriculture, Praeger, New York

Connell, J., and M. Lipton, 1977, Assessing Village Labour Situations in Developing Countries, Oxford University Press, New Delhi

Coyle, R. G., 1972, Decision Analysis, Nelson, London

Dasgupta, B., 1977, Village Society and Labour Use. Oxford University Press, New Delhi

Fuller, M. F., and D. A. Lury, 1977, Statistics Workbook for Social Science Students, Philip Allen, Deddington 
Imboden, N., 1978, A Management Approach to Project Appraisal and Evaluation, OECD, Paris

Johnson, R. A., F. E. Kast and J. E. Rosenzweig, 1963, The Theory and Management of Systems, McGraw Hill, New York

Kirkpatrick, G., 1978, 'Review of Connell and Lipton, assessing village labour situations', The Economic Journal vol 88 no 351, pp 613-615, September

Klir, G. J., 1972, Trends in General Systems Theory, New York

Kulp, E. M., 1970, Rural Development Planning: Systems Analysis and Working Method, Praeger, New York

Livingstone, I., 1976, 'Experimentation in rural development: Kenya's special rural development programme', Agricultural Administration, vol 3, pp 217-233

Long, N., 1977, An Introduction to the Sociology of Rural Development, Tavistock, London

Lundquist, J., 1975, Regional Information and Regional Planning in Tanzania, in A. Kuklinski (ed), Regional Information and Regional Planning, Mouton, The Hague

McDonough, A. M., 1963, Information Economics and Management Systems, McGraw Hill, New York

McGee, B., 1973, Popper, Fontana Modern Masters Series, Fontana, London
McLoughlin, J. B., 1969, Urban and Regional Planning: A Systems Approach, Faber, London

Meier, G. M., 1977, On 'appropriate' policy technology for development, in M. Nash (ed), Essays on Economic Development and Cultural Change in Honor of Bert F. Hoselitz, Economic Development and Cultural Change, vol 25 supplement, University of Chicago Press

Popper, K., 1945, The Open Society and its Enemies, 2 vols, Routledge, London

- 1959, The Logic of Scientific Discovery, Hutchinson, London; first published in German in 1934

Sen, A. K., 1979, 'Personal utilities and public judgements: or what's wrong with welfare economics?', The Economic Journal, vol 89 no 355, pp 537-558, September

Shivji, I. G., 1975, Class Struggles in Tanzania, Tanzania Publishing House, Dar es Salaam

United Nations, 1978, Systematic Monitoring and Evaluation of Integrated Development Programmes: A Source Book, New York

United States Agency for International Development, 1973, Project Evaluation Workbook, Washington D.C.

World Bank, 1976, Operational Evaluation: World Bank Standards and Procedures, Washington DC

World Health Organisation, 1976, Methodology of Nutritional Surveillance, Technical Report no 593, Geneva 